\title{
Autoimmune thyroiditis in children and adolescents with type 1 diabetes mellitus is associated with elevated IgG4 but not with low vitamin D
}

\author{
Korcan Demir,, ${ }^{1}$ Mehmet Keskin, ${ }^{2}$ Yllmaz Kör, ${ }^{2}$ Murat Karaoğlan, ${ }^{2}$ \\ Özlem Gümüs̨tekin Bülbül ${ }^{3}$ \\ ${ }^{1}$ Division of Pediatric Endocrinology, Children's Hospital; ${ }^{2}$ Department of Pediatric Endocrinology, Gaziantep University; \\ ${ }^{3}$ Division of Biochemistry, Children's Hospital; Gaziantep, Türkiye
}

\begin{abstract}
OBJECTIVE: To assess levels of vitamin D and of immunoglobulin G subclasses in children and adolescents with type 1 Diabetes Mellitus with or without autoimmune thyroiditis. DESIGN: Among 213 patients with type 1 diabetes, the cases with thyroid-specific autoantibodies formed Group 1 [n=19, M/F: 7/12, median age 13 years (10.1-14.7)]. Nineteen age-, gender-, and diabetes duration-matched cases with type 1 diabetes without any other systemic disease were designated as controls [Group 2, M/F: 7/12, median age 12.9 years (10.5-14.9)]. RESULTS: Levels of thyroid hormones, vitamin D, total IgG and IgG subclasses, as well as IgG subclasses/ total IgG ratios were similar between the groups. Five cases $(26 \%)$ in Group 1 had IgG4 levels $>+2$ SDS, whereas there were no such cases in Group $2(p=0.046)$. These five patients had similar clinical features but higher median IgG4 levels and IgG4/Total IgG ratios compared to the subjects with IgG4 levels < + 2 SDS in Group 1 and Group 2. CONCLUSIONS: There was no difference of vitamin $D$ levels between the groups. Only a small percentage of patients with type 1 diabetes also having autoimmune thyroiditis had elevated serum IgG4 levels, revealing the heterogeneity of autoimmune thyroiditis and existence of IgG4 thyroiditis in the pediatric age group. Total IgG, the other IgG subclasses, and vitamin D levels did not differ in patients with autoimmune thyroiditis and type 1 diabetes compared to those suffering only from type 1 diabetes.
\end{abstract}

Key words: Autoimmune thyroiditis, Immunoglobulin G subclasses, Type 1 diabetes, Vitamin D

Address for correspondence:

Dr. Korcan Demir, Cocuk Endokrinolojisi Poliklinigi, Cocuk

Hastaliklari Hastanesi, 27560, Gaziantep, Türkiye,

Tel.: +90 505525 2743, Fax: +90 3423600290 ,

E-mail: korcandemir@gmail.com

Received 18-07-2013, Accepted 20-12-2014

\section{INTRODUCTION}

Autoimmune thyroiditis is the most frequent autoimmune disease accompanying type 1 diabetes in up to $30 \%$ of children and adolescents suffering from type 1 Diabetes Mellitus. ${ }^{1-3}$ Typical features of the 
disease are presence of thyroid specific antibodies (antithyroid peroxidase antibodies and antithyroglobulin antibodies) in serum and varying degrees of thyroid dysfunction. ${ }^{1}$ While the exact pathogenesis is unclear, female gender, certain HLA types, polymorphisms in the CTLA-4 gene, chromosomal diseases, puberty, smoking, endocrine disruptors, and Yersinia infections are among the risk factors for autoimmune thyroiditis. ${ }^{4}$ Increasing age, longer duration of diabetes, and presence of anti-GAD antibody have also been found to be associated with autoimmune thyroiditis in patients with type 1 diabetes. ${ }^{5,6}$

Vitamin D is a fat-soluble vitamin which is mainly involved in calcium/phosphate homeostasis and bone mineralization. However, increasing evidence points to the role of vitamin D in cell proliferation and differentiation, regulation of the immune system, glucose metabolism, and cardiovascular health. ${ }^{7}$ Recently, children and adults with Hashimoto's thyroiditis were found to have significantly lower $25(\mathrm{OH})$ vitamin $\mathrm{D}$ [25(OH)D] levels and higher frequency of vitamin $\mathrm{D}$ deficiency compared to controls. ${ }^{8-10}$ On the other hand, the role of vitamin D levels in Hashimoto's thyroiditis accompanying type 1 diabetes, for which deficiency of vitamin $\mathrm{D}$ and genetic variations in vitamin D-related genes were proposed as being predisposing factors, has not yet been investigated. ${ }^{11}$

Recently, in adults who required total thyroidectomy, a subtype of Hashimoto's thyroiditis was described, termed "IgG4 thyroiditis", which is characterized by an abundance of IgG4-positive plasma cells and fibrosis in the thyroid tissue, lower female/male ratio, higher percentage of diffuse low echogenicity at ultrasonography, more rapid clinical progression, and higher serum levels of IgG4 and thyroid autoantibodies. ${ }^{12}$ There are a limited number of studies regarding $\operatorname{IgG}$ subclasses in children with type 1 diabetes or autoimmune thyroiditis. To the best of our knowledge, their association with autoimmune thyroiditis and type 1 diabetes has not been evaluated in relevant studies.

In the present study, we aimed to put forward the hypothesis that low vitamin D levels and/or elevated IgG4 levels might be associated with autoimmune thyroiditis in patients with type 1 diabetes.

\section{METHODS}

\section{Subjects and Setting}

Among 213 type 1 diabetes patients regularly followed in the two pediatric endocrinology clinics in the city of Gaziantep, Turkey, 25 cases $(11.7 \%)$ were found to have autoimmune thyroiditis as determined by presence of thyroid-specific autoantibodies including antithyroid peroxidase antibodies (TPOAb, reference range 0-35 IU/mL) and antithyroglobulin antibodies (TGAb, reference range $0-40 \mathrm{IU} / \mathrm{mL}$ ). ${ }^{13}$ Six of them could not finally be included despite several unsuccessful attempts to make contact, and the remaining 19 cases formed Group 1 (type 1 diabetes + autoimmune thyroiditis). Among the subjects with type 1 diabetes who were enrolled in the study, age-, gender-, and diabetes duration-matched cases without any other systemic disease were designated as controls $(n=19$, Group 2). Furthermore, the participants of Group 1 were assigned to two subgroups: those who had an IgG4 level > +2 SD score (Subgroup 1) and those with an IgG4 level <+2 SD score (Subgroup 2). Informed consent was obtained from both the parents and subjects. The study protocol was in compliance with the Declaration of Helsinki and approved by the institutional ethical review board.

\section{Clinical and Laboratory Procedures}

During a period free of infection or inflammation, all the subjects underwent physical examination (including assessment of weight, height, pubertal state, and thyroid size) and blood sampling following descriptive data collection (including exposure to smoke, family history of autoimmune thyroiditis, insulin dose, and L-thyroxine use). None of the patients was using vitamin D preparations or smoking. Regular exposure of participants to second-hand smoke within the previous six months was considered as passive smoking. ${ }^{14}$ Thyroid size was evaluated clinically according to the World Health Organization criteria. ${ }^{15}$ Body mass index (BMI) was calculated as weight $(\mathrm{kg})$ divided by the square of height (m). Auxological data were converted to standard deviation scores (SDS) by using data from the National Health and Nutrition Examination Survey. ${ }^{16}$

Complete blood count and hemoglobin A1c analyses were performed on the day of evaluation. Serum 
specimens for free thyroxine (fT4), thyroid-stimulating hormone (TSH), TgAb, TPOAb, calcium, phosphorus, alkaline phosphatase, parathormone, $25(\mathrm{OH})$ vitamin $\mathrm{D}$, total immunoglobulin $\mathrm{G}(\mathrm{IgG})$, and $\mathrm{IgG}$ subclasses were stored at $-20^{\circ} \mathrm{C}$. Biochemical and hormonal analyses were performed using Abbott Architect ci8200 (Abbott Laboratories, Illinois, USA) by using standard methodology. Serum IgG, IgG1, IgG2, $\mathrm{IgG} 3$, and $\mathrm{IgG} 4$ were measured by the nephelometric method (Beckman Coulter Immage 800, Beckman Coulter International SA, Nyon, Switzerland) using commercially available kits (Binding Site Group Ltd, Birmingham, UK). The interpretation of levels of IgG and $\mathrm{IgG}$ subclasses was carried out using reference values generated from healthy Turkish children. ${ }^{17}$ Ultrasonography was performed to establish the size and echogenicity characteristics of the thyroid in patients with autoimmune thyroiditis. Thyroid sizes of the subjects were converted to SDS by using data reported by Kurtoglu et al. ${ }^{18}$

\section{Statistical Analyses}

The data were analyzed using computer software SPSS 15.0 (Chicago, Illinois, USA). All continuous variables were compared with nonparametric tests (Mann-Whitney U-test and Kruskal-Wallis test), since the Shapiro-Wilk test demonstrated that few numerical variables were normally distributed among the groups compared. Comparison of study variables was first made between Groups 1 and 2. The chi-square or Fisher's exact test were used to compare categorical variables. Univariate correlation analysis was performed using Spearman's rank correlation coefficient. A p-value of $<0.05$ was chosen to represent statistical significance. Comparisons between subgroups and controls were made using the Kruskal-Wallis test followed by the Mann-Whitney U-test with Bonferroni correction. A $p$-value of $<0.0167$ was considered to represent a statistically significant difference: $p$-value $=0.05 \times 2 / \mathrm{k}(\mathrm{k}-1)$, where $\mathrm{k}$ represents the number of comparisons. ${ }^{19}$ All data were presented as median $\left(25^{\text {th }}-75^{\text {th }}\right.$ percentiles $)$ or $\mathrm{n}(\%)$.

\section{RESULTS}

Group 1 consisted of 19 subjects with type 1 diabetes and autoimmune thyroiditis [(M/F: 7/12, median age 13 years (10.1-14.7), median disease duration 2.9 years (0.4-5.3)]. Group 2 included 19 control cases with type 1 diabetes [M/F: 7/12, median age 12.9 years (10.5-14.9), median disease duration 3.2 years (1.5-5.1)]. The two groups were found to have similar clinical characteristics including known risk factors for autoimmune thyroiditis (Table 1). None of the patients was obese or an active smoker. All of the subjects were receiving basal-bolus insulin regimen. One of the patients was using L-thyroxine $(2.7 \mu \mathrm{g} /$ $\mathrm{kg} / \mathrm{d}$ ) due to overt hypothyroidism.

Table 1. Clinical characteristics of the subjects with (Group 1) and without (Group 2) autoimmune thyroiditis

\begin{tabular}{lccc}
\hline & Group 1 (n=19) & Group 2 (n=19) & $p$ \\
\hline Age (years) & $13.0(10.1-14.7)$ & $12.9(10.5-14.9)$ & 0.931 \\
Gender (female) & $12(63 \%)$ & $12(63 \%)$ & 0.999 \\
Age at diagnosis (years) & $8.1(5.8-12.8)$ & $9.0(7.8-11.6)$ & 0.665 \\
Diabetes duration (years) & $2.9(0.4-5.3)$ & $3.2(1.5-5.1)$ & 0.729 \\
Weight SDS & $-0.04(-0.84-0.56)$ & $-0.07(-0.71-0.67)$ & 0.840 \\
Height SDS & $-0.42(-0.89-0.46)$ & $-0.88(-2.10--0.33)$ & 0.146 \\
BMI SDS & $0.29(-0.15-0.70)$ & $0.25(-0.58-1.32)$ & 0.885 \\
Exposure to smoke & $9(47 \%)$ & $5(26 \%)$ & 0.138 \\
Family history of autoimmune thyroiditis & $5(26 \%)$ & $2(11 \%)$ & 0.209 \\
Goiter & $2(10 \%)$ & $0(0 \%)$ & 0.486 \\
Pubertal subjects & $13(68 \%)$ & $13(68 \%)$ & 0.999 \\
Daily insulin dose (units/kg/d) & $1(0.7-1)$ & $1.1(0.8-1.6)$ & 0.189 \\
\hline
\end{tabular}

Results are given as median (25th - 75th percentiles) or n (\%). SDS: standard deviation score; BMI: body mass index. 
One subject from Group 1 had iron deficiency anemia. None of the subjects had leukocytosis, neutrophilia, lymphocytosis or thrombocytosis. Group 1 and Group 2 were similar regarding hemoglobin A1c [10.3\% (8 - 11.3) vs. 8.7\% (7.7 - 10.1), p=0.181], fT4 [1.05 ng/dL (1.01 - 1.11) vs. $1.06 \mathrm{ng} / \mathrm{dL}(0.99-1.13)$, $\mathrm{p}=0.931]$, and TSH levels $[1.9 \mathrm{mIU} / \mathrm{L}(1.1-2.5)$ vs. $1.4 \mathrm{mIU} / \mathrm{L}(1.1-2.7), \mathrm{p}=0.418]$. As expected, levels of thyroid-specific autoantibodies were significantly higher in Group 1 [TgAb, $28.5 \mathrm{IU} / \mathrm{mL}$ (2.95 - 154.9) vs. $0.86 \mathrm{IU} / \mathrm{mL}(0.77-1.61), \mathrm{p}=0.001$; TPOAb, 173.7 $\mathrm{IU} / \mathrm{mL}(47.4-399.9)$ vs. $0.18 \mathrm{IU} / \mathrm{mL}(0.06-0.25)$, $\mathrm{p}=0.001]$. Positivity rates of TPOAb, TgAb, and TPOAb\&TgAb in Group 1 were 94.7\% $(n=18)$, $52.6 \%(\mathrm{n}=10)$, and $47.3 \%(\mathrm{n}=9)$, respectively. Calcium, phosphorus, and alkaline phosphatase levels were all within normal ranges and did not differ between the groups (data not shown). In Group 1, ultrasonographic evaluation of the thyroid $(n=14$, $73.7 \%$ ) yielded a volume SDS of $0.01(-0.92-0.42)$, coarse echogenicity in nine cases $(64.3 \%)$, and normal echogenicity in five subjects $(35.7 \%)$.

Serum vitamin D levels of the subjects were all below $20 \mathrm{ng} / \mathrm{mL}$ in both groups, indicating that none of the patients was vitamin D sufficient (Table 2). ${ }^{20}$
Levels of vitamin $\mathrm{D}$, total $\mathrm{IgG}$ and $\mathrm{IgG}$ subclasses, ratios of $\mathrm{IgG}$ subclasses to total $\mathrm{IgG}$, and number of subjects with IgG1, IgG2, and IgG3 levels > + 2 SD were similar between the groups. IgG4 levels of the patients are shown in Figure 1. Five patients (26\%) in Group 1 had IgG4 levels above the upper limit of

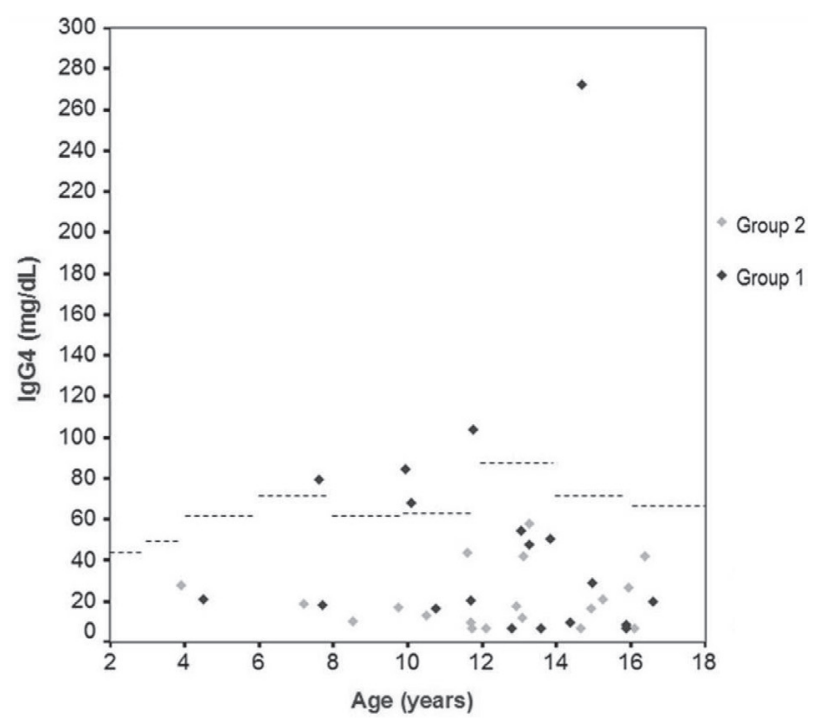

Figure 1. Levels of IgG4 in cases with (Group 1) and without (Group 2) autoimmune thyroiditis. Dotted lines indicate +2 $\mathrm{SD}$ of relevant age groups.

Table 2. Vitamin D, parathormone, and immunoglobulin results of the groups

\begin{tabular}{lccc}
\hline & Group 1 $(\mathbf{n}=\mathbf{1 9})$ & Group 2 $(\mathbf{n}=\mathbf{1 9})$ & $p$ \\
\hline 25-OH Vitamin D (ng/mL) & $10.7(8.8-13.3)$ & $9.8(7.7-11)$ & 0.284 \\
PTH $(\mathrm{pg} / \mathrm{mL})$ & $48.1(35.7-54.0)$ & $47.2(29.9-65.8)$ & 0.988 \\
Total IgG (mg/dL) & $1100(948-1300)$ & $1020(790-1240)$ & 0.123 \\
IgG1 (mg/dL) & $727(640-843)$ & $680(508-806)$ & 0.191 \\
IgG1/Total IgG & $0.68(0.62-0.73)$ & $0.67(0.62-0.69)$ & 0.773 \\
IgG1 level > + 2 SDS & $3(16 \%)$ & $1(5 \%)$ & 0.604 \\
IgG2 (mg/dL) & $266(211-399)$ & $222(184-299)$ & 0.096 \\
IgG2/Total IgG & $0.25(0.22-0.32)$ & $0.25(0.21-0.28)$ & 0.370 \\
IgG2 level > + 2 SDS & $7(37 \%)$ & $2(10 \%)$ & 0.124 \\
IgG3 (mg/dL) & $82(57-129)$ & $64(53-107)$ & 0.506 \\
IgG3/Total IgG & $0.075(0.046-0.107)$ & $0.077(0.059-0.105)$ & 0.563 \\
IgG3 level > + 2 SDS & $9(47 \%)$ & $5(26 \%)$ & 0.179 \\
IgG4 (mg/dL) & $20.8(9.6-68.2)$ & $17.2(9.8-27.6)$ & 0.130 \\
IgG4/Total IgG & $0.025(0.009-0.055)$ & $0.017(0.009-0.033)$ & 0.223 \\
IgG4 level > + 2 SDS & $5(26 \%)$ & $0(0 \%)$ & 0.046 \\
\hline
\end{tabular}

Results are given as median (25th - 75th percentiles) or n (\%). PTH: parathormone; IgG: immunoglobulin G; SDS: standard deviation score. 
age-related reference range, while all of the subjects in Group 2 had normal IgG4 levels $(p=0.046)$. Correlation analyses in Group 1 revealed that vitamin D and IgG4 levels were not correlated with any of the clinical and laboratory variables studied.

Clinical and radiological features and vitamin D levels were similar among the subgroups and controls. Levels of thyroid-specific autoantibodies did not differ between the subgroups but were higher compared to those of controls. Positivity rates of antibodies among Subgroup 1 and Subgroup 2 were similar: TPOAb, $80 \%(n=4)$ vs. $100 \%(n=14), p=0.263 ; \operatorname{TgAb}, 60 \%$ $(\mathrm{n}=3)$ vs. $50 \%(\mathrm{n}=7), \mathrm{p}=0.999$; TPOAb and $\mathrm{TgAb}$, $40 \%(\mathrm{n}=2)$ vs. $50 \%(\mathrm{n}=7), \mathrm{p}=0.999$, respectively. IgG4 levels and IgG4/Total IgG ratios in Subgroup
1 were higher than those of Subgroup 2 and controls (Table 3).

\section{DISCUSSION}

To the best of our knowledge, only varying degrees of deficiencies have been reported in studies regarding serum $\mathrm{IgG}$ subclasses in patients with type 1 diabetes. ${ }^{21}$ In the present study, we found that serum IgG4 levels were above the upper limit in nearly one fourth of patients with type 1 diabetes and autoimmune thyroiditis, while none of the serum IgG4 levels exceeded the upper limits of normal in age-, sex-, and diabetes duration-matched control cases without autoimmune thyroiditis. This finding provides further evidence that autoimmune thyroiditis is a heterogene-

Table 3. Comparisons between patients with type 1 diabetes, autoimmune thyroiditis, and an IgG4 level $>+2$ SD score (Subgroup 1 ), patients with type 1 diabetes, autoimmune thyroiditis, and an IgG4 level <+2 SD score (Subgroup 2) and patients with type 1 diabetes without autoimmune thyroiditis (Group 2).

\begin{tabular}{|c|c|c|c|c|c|c|c|}
\hline & \multicolumn{2}{|c|}{ Group $1(n=19)$} & \multirow[b]{3}{*}{$\begin{array}{c}\text { Group } 2 \\
(\mathrm{n}=19)\end{array}$} & \multicolumn{4}{|c|}{$p$ values } \\
\hline & \multirow[b]{2}{*}{$\begin{array}{l}\text { Subgroup } 1 \\
\quad(n=5)\end{array}$} & \multirow[b]{2}{*}{$\begin{array}{c}\text { Subgroup } 2 \\
(n=14)\end{array}$} & & \multicolumn{3}{|c|}{ Subgroup 1} & \multirow[b]{2}{*}{$\begin{array}{l}\text { Subgroup } 2 \\
\text { vs. Group } 2 \\
\end{array}$} \\
\hline & & & & $\begin{array}{l}\text { All three } \\
\text { groups }\end{array}$ & $\begin{array}{c}\text { vs. } \\
\text { Subgroup } 2\end{array}$ & $\begin{array}{l}\text { Subgroup } 1 \\
\text { vs. Group } 2\end{array}$ & \\
\hline Age (years) & $10.1(8.8-13.2)$ & $13.4(11.5-15.2)$ & $12.9(10.5-14.9)$ & 0.317 & 0.138 & 0.271 & 0.500 \\
\hline Gender (female) & $3(60 \%)$ & $9(64 \%)$ & $12(63 \%)$ & 0.999 & 0.999 & 0.999 & 0.947 \\
\hline $\begin{array}{l}\text { Age at diagnosis } \\
\text { (years) }\end{array}$ & $7.3(6.1-8.8)$ & $9.2(5.6-13)$ & $9.0(7.8-11.6)$ & 0.419 & 0.579 & 0.126 & 0.999 \\
\hline $\begin{array}{l}\text { Diabetes duration } \\
\text { (years) }\end{array}$ & $3.6(1.9-4.8)$ & $2.1(0.4-7.4)$ & $3.2(1.5-5.1)$ & 0.747 & 0.547 & 0.749 & 0.536 \\
\hline Exposure to smoke & $4(80 \%)$ & $5(36 \%)$ & $5(26 \%)$ & 0.108 & 0.293 & 0.092 & 0.734 \\
\hline $\begin{array}{l}\text { Family history } \\
\text { of autoimmune } \\
\text { thyroiditis }\end{array}$ & $3(60 \%)$ & $2(14 \%)$ & $2(10 \%)$ & 0.066 & 0.161 & 0.071 & 0.999 \\
\hline Goiter & $0(0 \%)$ & $2(14 \%)$ & $0(0 \%)$ & 0.243 & 0.964 & $\mathrm{~N} / \mathrm{A}$ & 0.336 \\
\hline Coarse echogenicity ${ }^{\alpha}$ & $3(75 \%)$ & $6(60 \%)$ & - & 0.999 & N/A & $\mathrm{N} / \mathrm{A}$ & $\mathrm{N} / \mathrm{A}$ \\
\hline Thyroid volume SDS ${ }^{\alpha}$ & $0.1(0.01-1.26)$ & $-0.63(-1.24-0.42)$ & - & 0.188 & $\mathrm{~N} / \mathrm{A}$ & $\mathrm{N} / \mathrm{A}$ & $\mathrm{N} / \mathrm{A}$ \\
\hline Pubertal subjects & $3(60 \%)$ & $10(71 \%)$ & $13(68 \%)$ & 0.999 & 0.999 & 0.999 & 0.999 \\
\hline $\begin{array}{l}25(\mathrm{OH}) \text { Vitamin D } \\
(\mathrm{ng} / \mathrm{mL})\end{array}$ & $11.3(8.7-16.2)$ & $10.5(8.7-13.3)$ & $9.8(7.7-11)$ & 0.473 & 0.578 & 0.271 & 0.423 \\
\hline $\operatorname{TgAb}(\mathrm{IU} / \mathrm{mL})$ & $12.1(1.9-80.0)$ & $34.8(5.4-298.2)$ & $0.86(0.77-1.61)$ & 0.001 & 0.459 & 0.001 & 0.001 \\
\hline TPOAb (IU/mL) & $46.3(23.9-593.0)$ & $192.7(67.7-365.6)$ & $0.18(0.06-0.25)$ & 0.001 & 0.517 & 0.001 & 0.001 \\
\hline IgG4 (mg/dL) & 84.5 (73.9-188) & $18.9(8.1-33.7)$ & $17.2(9.8-27.6)$ & 0.002 & 0.001 & 0.001 & 0.855 \\
\hline IgG4/Total IgG & $0.080(0.060-0.114)$ & $0.017(0.007-0.036)$ & $0.017(0.009-0.033)$ & 0.002 & 0.001 & 0.001 & 0.855 \\
\hline
\end{tabular}

Results are given as n (\%) and median (25th - 75 th percentile); ${ }^{\circ}$ : Ultrasonography could not be performed in 1 case from Subgroup 1 and 4 cases from Subgroup 2. SDS: standard deviation score; TgAb: antithyroglobulin antibodies; TPOAb: antithyroid peroxidase antibodies; IgG: immunoglobulin G; N/A: not applicable. 
ous disease and suggests that IgG4 thyroiditis might exist in children with type 1 diabetes as well.

IgG4 thyroiditis was first described by Li et al. following the observation of a high number of IgG4positive plasma cells in thyroid tissue in some of the adults who required total thyroidectomy due to Hashimoto's thyroiditis (mean disease duration 9.6 years). Serum IgG4 levels, which could be measured in a subset of patients, TgAb and TPOAb levels, Lthyroxine doses, number of patients with subclinical hypothyroidism, and male/female ratio were higher and disease duration was shorter in the latter cases compared to those of subjects with non-IgG4 thyroiditis. ${ }^{12}$ Histopathological evaluation was not made in the present study given the lack of clinical necessity and ethical issues. Our subgroup analysis revealed that subjects with type 1 diabetes and autoimmune thyroiditis accompanied by elevated IgG4 levels had similar clinical, imaging, and laboratory features with respect to the other subgroup despite a tendency towards higher rates of family history of autoimmune thyroiditis and exposure to smoke and lower levels of thyroid autoantibodies.

The role of smoking in thyroid autoimmunity is complex. In adults, a relationship between active smoking and Hashimoto's thyroiditis has been suggested. However, active smoking, but not passive smoking, has recently been reported to be protective against thyroid-specific autoantibody positivity. ${ }^{22-24}$ As far as we are aware, no such data exist regarding children or adolescents with type 1 diabetes. In our cases, none of whom were smokers, passive smoking was more common in Group 1. Interestingly, this difference seems to be associated with subjects with elevated IgG4. In contrast with recent reports, despite being statistically insignificant, thyroid-specific autoantibody median levels were lower in subjects with elevated IgG4 (Subgroup 1), of whom 80\% were exposed to smoke, compared to that of subjects with normal IgG4 (Subgroup 2). Smoking status of IgG4 thyroiditis patients, in whom mean thyroid-specific autoantibody levels were notably high, was not mentioned in the original report. ${ }^{12} \mathrm{IgG} 4$ levels were analyzed in several studies performed in nicotine consumers or active smokers and no high levels were detected. ${ }^{25-27}$ Further studies in children with autoimmune thyroiditis using biomarkers of passive smoking including cotinine, nicotine, or exhaled carbon monoxide would be of benefit.

IgG4 is the least abundant subclass in blood and has the weakest capability of interacting with classical Fc gamma receptors and C1q. ${ }^{17,28}$ Accordingly, it is generally non-pathogenic. However, purified IgG4 from humans with an endemic form of pemphigus foliaceus has resulted in a similar clinical picture in mice. ${ }^{28}$ In IgG4-related sclerosing disease, which is a steroid-responsive systemic autoimmune syndrome characterized by tumor-like lymphoplasmacytic infiltration of various tissues, sclerosis and elevated serum IgG4 level, and possibly an IgG4 thyroiditis subgroup of Hashimoto's thyroiditis, elevated blood levels of IgG4 appear to be the consequence of increased numbers of IgG4-positive plasma cells in the tissues rather than the cause of disease. ${ }^{12,28}$ One third to half of patients with type 1 diabetes patients and thyroid autoantibody positivity have been reported to develop subclinical or overt hypothyroidism during follow-up. ${ }^{29,30}$ As was also shown in adults with Hashimoto's thyroiditis, elevated IgG4 levels in our study group may be associated with the frequency and tempo of progression to hypothyroidism in type 1 diabetes. $^{12}$

Among the endocrine glands, the pancreas and pituitary are also involved in IgG4-related sclerosing disease. Autoimmune pancreatitis is one of the commonest presentations, characterized by mild abdominal symptoms, obstructive jaundice, and enlarged pancreas. ${ }^{31}$ Headache and visual disturbances with or without hypopituitarism are associated with IgG4-related autoimmune hypophisitis. Cranial imaging reveals sellar mass and/or thickened pituitary stalk. ${ }^{32,33}$ Our cases with elevated IgG4 levels were not evaluated thoroughly regarding these conditions; however, absence of relevant symptoms or laboratory findings (e.g. central hypothyroidism) militates against pancreatic or pituitary involvement.

In the present study, all of the vitamin D levels were found to be below the lower limit of sufficiency $(20 \mathrm{ng} / \mathrm{mL})$. A recent evaluation of healthy Turkish children between 1 and 16 years of age in Ankara revealed that $14.5 \%$ of cases had $25(\mathrm{OH}) \mathrm{D}$ levels below $20 \mathrm{ng} / \mathrm{mL} .{ }^{34}$ However, a much higher percentage of children and adolescents with type 1 diabetes 
(71\%) from the same city were found to have $25(\mathrm{OH})$ $\mathrm{D}$ levels below this limit. ${ }^{35}$ Whatever the underlying cause, vitamin D deficiency did not appear to be associated with autoimmune thyroiditis in subjects with type 1 diabetes in our study, unlike other studies. Camurdan et al reported that vitamin D deficiency was nearly four times more prevalent and $25(\mathrm{OH}) \mathrm{D}$ levels were significantly lower $(31.2 \pm 11.5 \mathrm{nmol} / \mathrm{L})$ in 78 children with Hashimoto's thyroiditis (hypothyroidism, 6.4\%; subclinical hypothyroidism, 15.4\%, euthyroidism, $78.2 \%)$ compared to controls $(n=74$, $57.9 \pm 19.7 \mathrm{nmol} / \mathrm{L}$ ) (conversion factor for $25(\mathrm{OH})$ $\mathrm{D}: \mathrm{ng} / \mathrm{mL}=\mathrm{nmol} / \mathrm{L} / 2.496) .{ }^{8}$ In agreement with our findings, a longitudinal follow-up of adult subjects revealed that prevalence of vitamin D deficiency comparable between cases who developed TPOAb during follow-up compared to those who did not, resulting in the suggestion that vitamin D deficiency is not associated with early thyroid autoimmunity. ${ }^{36}$

In conclusion, the present study demonstrated that a subset of cases with type 1 diabetes and autoimmune thyroiditis have elevated IgG4 levels, suggesting existence of IgG4 thyroiditis. Total IgG, other IgG subclasses, and vitamin D levels were found to be not associated with autoimmune thyroiditis in type 1 diabetes. In further studies, the prognostic value of increased serum IgG4 levels for thyroid dysfunction in type 1 diabetes should be investigated.

\section{CONFLICT OF INTEREST}

None.

\section{FUNDING}

This work was supported by a grant from the Pediatric Endocrinology and Diabetes Society, Turkey.

\section{REFERENCES}

1. Karavanaki K, Kakleas K, Paschali E, et al, 2009 Screening for associated autoimmunity in children and adolescents with type 1 diabetes mellitus (T1DM). Horm Res 71: 201-206.

2. Ergür AT, Oçal G, Berberoğlu M, et al, 2010 Celiac disease and autoimmune thyroid disease in children with type 1 diabetes mellitus: clinical and HLA-genotyping results J Clin Res Pediatr Endocrinol 2: 151-154.

3. Keskin M, Keskin O, Temel L, et al, 2010 Screening frequency of celiac disease and autoimmune thyroiditis in children and adolescents with type 1 diabetes mellitus in Turkey and comparison with last surveys. Endocrinologist 20: 171-173.

4. Guarneri F, Benvenga S, 2007 Environmental factors and genetic background that interact to cause autoimmune thyroid disease. Curr Opin Endocrinol Diabetes Obes 14: 398-409.

5. Kakleas K, Paschali E, Kefalas N, et al, 2009 Factors for thyroid autoimmunity in children and adolescents with type 1 diabetes mellitus. Ups J Med Sci 114: 214-220.

6. Barker JM, 2006 Clinical review: Type 1 diabetesassociated autoimmunity: natural history, genetic associations, and screening. J Clin Endocrinol Metab 91: 1210-1217.

7. Weisman Y, 2010 Non-classic unexpected functions of vitamin D. Pediatr Endocrinol Rev 8: 103-107.

8. Camurdan OM, Döğer E, Bideci A, Celik N, Cinaz P, 2012 Vitamin D status in children with Hashimoto thyroiditis. J Pediatr Endocrinol Metab 25: 467-470.

9. Tamer G, Arik S, Tamer I, Coksert D, 2011 Relative vitamin D insufficiency in Hashimoto's thyroiditis. Thyroid 21: 891-896.

10. Kivity S, Agmon-Levin N, Zisappl M, et al, 2011 Vitamin D and autoimmune thyroid diseases. Cell Mol Immunol 8: 243-247.

11. Wolden-Kirk H, Overbergh L, Christesen HT, Brusgaard K, Mathieu C, 2011 Vitamin D and diabetes: its importance for beta cell and immune function. Mol Cell Endocrinol 347: 106-120.

12. Li Y, Nishihara E, Hirokawa M, Taniguchi E, Miyauchi A, Kakudo K, 2010 Distinct clinical, serological, and sonographic characteristics of hashimoto's thyroiditis based with and without IgG4-positive plasma cells. J Clin Endocrinol Metab 95: 1309-1317.

13. Dayan CM, Daniels GH, 1996 Chronic autoimmune thyroiditis N Engl J Med 335: 99-107.

14. Soldin OP, Goughenour BE, Gilbert SZ, Landy HJ, Soldin SJ, 2009 Thyroid hormone levels associated with active and passive cigarette smoking. Thyroid 19: 817-823.

15. WHO document. Assessment of iodine deficiency disorders and monitoring of their elimination. A guide for programme managers. Geneva: 2001. WHO/NHD/01.1, 2001.

16. National Center for Health Statistics (2000) CDC Growth Charts, United States. http://www.cdc.gov/growthcharts/ percentile_data_files.htm. Accessed April 20, 2012.

17. Aksu G, Genel F, Koturoğlu G, Kurugöl Z, Kütükçüler N, 2006 Serum immunoglobulin (IgG, IgM, IgA) and IgG subclass concentrations in healthy children: a study using nephelometric technique. Turk J Pediatr 48: 19-24.

18. Kurtoglu S, Covut IE, Kendirci M, Uzum K, Durak AC, Kiris A, 1995 Normal thyroid volume of children in Turkey: Pilot study in Kayseri province. IDD Newsletter 11: 41-42.

19. Cleophas TJ, Zwinderman AH, Cleophas TF, Cleophas 
EP, 2009 Controlling the risk of false positive clinical trials. In: Cleophas TJ, Zwinderman AH, Cleophas TF, Cleophas EP (eds) Statistics applied to clinical trials, 4th ed, Springer, Dordrecht; pp, 107-111.

20. Misra M, Pacaud D, Petryk A, Collett-Solberg PF, Kappy M, 2008 Vitamin D deficiency in children and its management: review of current knowledge and recommendations. Pediatrics 122: 398-417.

21. Pastorino AC, Jacob CMA, Grumach AS, 1994 Subclasses de IgG e sua importância em pediatria. Pediatria (Sao Paulo) 16: 60-66.

22. Vestergaard P, 2002 Smoking and thyroid disorders - a meta-analysis. Eur J Endocrinol 146: 153-161.

23. Krassas GE, Wiersinga W, 2006 Smoking and autoimmune thyroid disease: the plot thickens. Eur J Endocrinol 154: 777-780.

24. Effraimidis G, Tijssen JG, Wiersinga WM, 2009 Discontinuation of smoking increases the risk for developing thyroid peroxidase antibodies and/or thyroglobulin antibodies: a prospective study. J Clin Endocrinol Metab 94: 1324-1328.

25. Al-Ghamdi HS, Anil S, 2007 Serum antibody levels in smoker and non-smoker saudi subjects with chronic periodontitis. J Periodontol 78: 1043-1050.

26. Gyllén P, Andersson BA, Qvarfordt I, 2004 Smokeless tobacco or nicotine replacement therapy has no effect on serum immunoglobulin levels. Respir Med 98: 108-114.

27. Gunsolley JC, Pandey JP, Quinn SM, Tew J, Schenkein HA, 1997 The effect of race, smoking and immunoglobulin allotypes on IgG subclass concentrations. J Periodontal Res 32: 381-387.

28. Aalberse RC, Stapel SO, Schuurman J, Rispens T, 2009
Immunoglobulin G4: an odd antibody. Clin Exp Allergy 39: 469-477.

29. Kordonouri O, Hartmann R, Deiss D, Wilms M, GrütersKieslich A, 2005 Natural course of autoimmune thyroiditis in type 1 diabetes: association with gender, age, diabetes duration, and puberty. Arch Dis Child 90: 411-414.

30. de Graaff LC, Martín-Martorell P, Baan J, Ballieux B, Smit JW, Radder JK, 2011 Long-term follow-up of organ-specific antibodies and related organ dysfunction in type 1 diabetes mellitus. Neth J Med 69: 66-71.

31. Guma M, Firestein GS, 2012 IgG4-related diseases. Best Pract Res Clin Rheumatol 26: 425-438.

32. Leporati P, Landek-Salgado MA, Lupi I, Chiovato L, Caturegli P, 2011 IgG4-related hypophysitis: a new addition to the hypophysitis spectrum. J Clin Endocrinol Metab 96: 1971-1980.

33. Hattori Y, Tahara S, Ishii Y, et al, 2013 A case of IgG4related hypophysitis without pituitary insufficiency. J Clin Endocrinol Metab 98: 1808-1811.

34. Akman AO, Tumer L, Hasanoglu A, Ilhan M, Caycı B, 2011 Frequency of vitamin D insufficiency in healthy children between 1 and 16 years of age in Turkey. Pediatr Int 53: 968-973.

35. Tunc O, Cetinkaya S, Kizilgün M, Aycan Z, 2011 Vitamin D status and insulin requirements in children and adolescent with type 1 diabetes. J Pediatr Endocrinol Metab 24: 1037-1041.

36. Effraimidis G, Badenhoop K, Tijssen JG, Wiersinga WM, 2012 Vitamin D deficiency is not associated with early stages of thyroid autoimmunity. Eur J Endocrinol 167: 43-48. 